\title{
Event review: The Archaeology Centre Knap-In and Goat Roast, Toronto, Canada
}

\author{
Amy Fox \\ Department of Anthropology, University of Toronto, Ontario, Canada. Email: amy.fox@mail.utoronto.ca
}

As a part of its programming line-up, The Archaeology Centre at the University of Toronto hosts a number of faculty and student-run interest groups that bring together archaeologists from the Toronto community. These groups foster interdepartmental and community collaboration among those who share similar research pursuits. In May 2015, the Lithics Interest Group and Food and Subsistence Interest Group organized an end-of-year knap-in and goat roast. Its goal was to introduce students to flintknapping and food production, and to celebrate an excellent year for the Archaeology Centre.

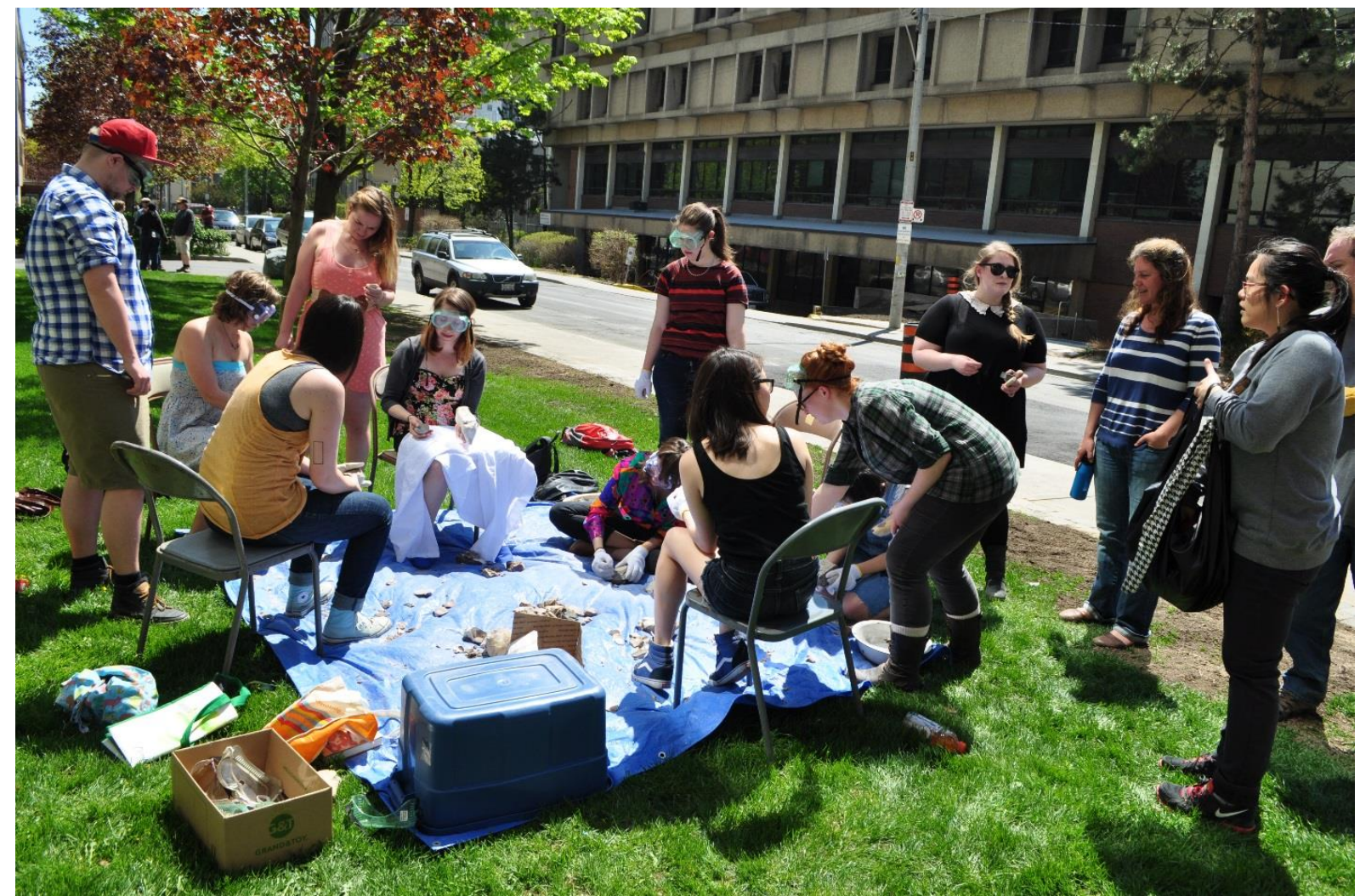

Figure 1. Students practice and learn flintknapping outside the Anthropology Building, University of Toronto (Photo: Paulina Dobrota).

Journal of Lithic Studies (2015) vol. 2, nr. 1, p. 169-173

doi:10.2218/jls.v2i1.1299

Published by the School of History, Classics and Archaeology, University of Edinburgh ISSN: 2055-0472. URL: http://journals.ed.ac.uk/lithicstudies/

This work is licensed under a Creative Commons Attribution 2.5 UK: Scotland License. 
For the Lithics Interest Group's knap-in, faculty members from the Department of Anthropology kindly donated flints and cherts from around the world, namely Jordan, Texas, and Ontario. On a particularly sunny afternoon after a long and cold winter, flintknappers gathered outside the university's Anthropology Building to practice their skills and learn new ones. The event was well-attended by both novice and experienced knappers, and a few pedestrians from the university campus were able to stop and learn what the anthropologists were doing out on the lawn as well. Instructors were on hand to give aid and lessons to those students who had never knapped stone before. There were a good number of students learning the basics of flake production for the first time, and instruction came with an emphasis on safety and a relatively loose chaîne opératoire approach. Many students showed up to enjoy the weather, socialize with fellow colleagues, and simply observe the flintknapping process.

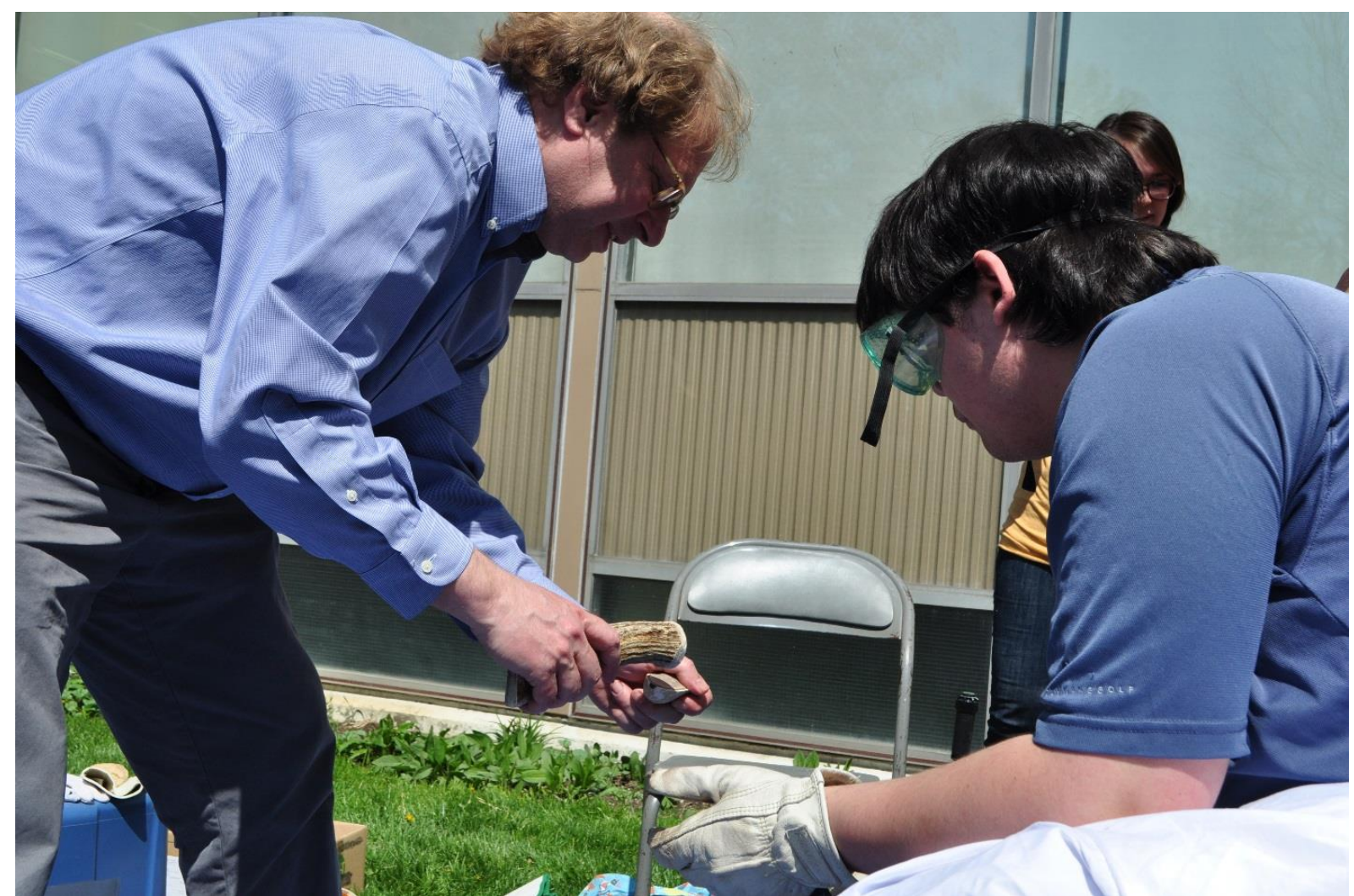

Figure 2. Professor Michael Chazan, Director of the Archaeology Centre, instructs on antler billeting. (Photo by Paulina Dobrota)

After about an hour of instruction and knapping out on the lawn, the students and university community gathered their flakes and moved upstairs to the Flintknapping Lab where they had the opportunity to put the flakes to use! The Archaeology Centre purchased a deceased goat from a local butcher, and with the guidance of the Food Interest Group, all attendees were able to skin and butcher the goat with the intent of gathering the hide and edible meat from the animal.

First, graduate students with experience in traditional butchering guided the hide extraction as many looked on in curiosity and fascination. Flakes with ideal skinning properties were not hard to find from the knap-in assemblage, and it was not long before the goat was ready to be butchered. The Food Interest Group gave general guidance on butchery and meat removal to different groups of students working on various parts of the animal. All attendees who were willing and interested in helping prepare the meat had the chance to choose their tools and carve off the goat, and some managed to use flakes of their own 
creation as well. Some commented on how surprisingly simple it was to use their flakes on the goat meat when cuts followed the natural fibrous lines inside the animal.

Those interested in hide production spent their time thoroughly cleaning and skinning the remaining meat from the hide with a few basic but effective scrapers. The hide was then salted and sealed for future tanning. The group's labours promise to provide a gorgeous leathered goat skin.

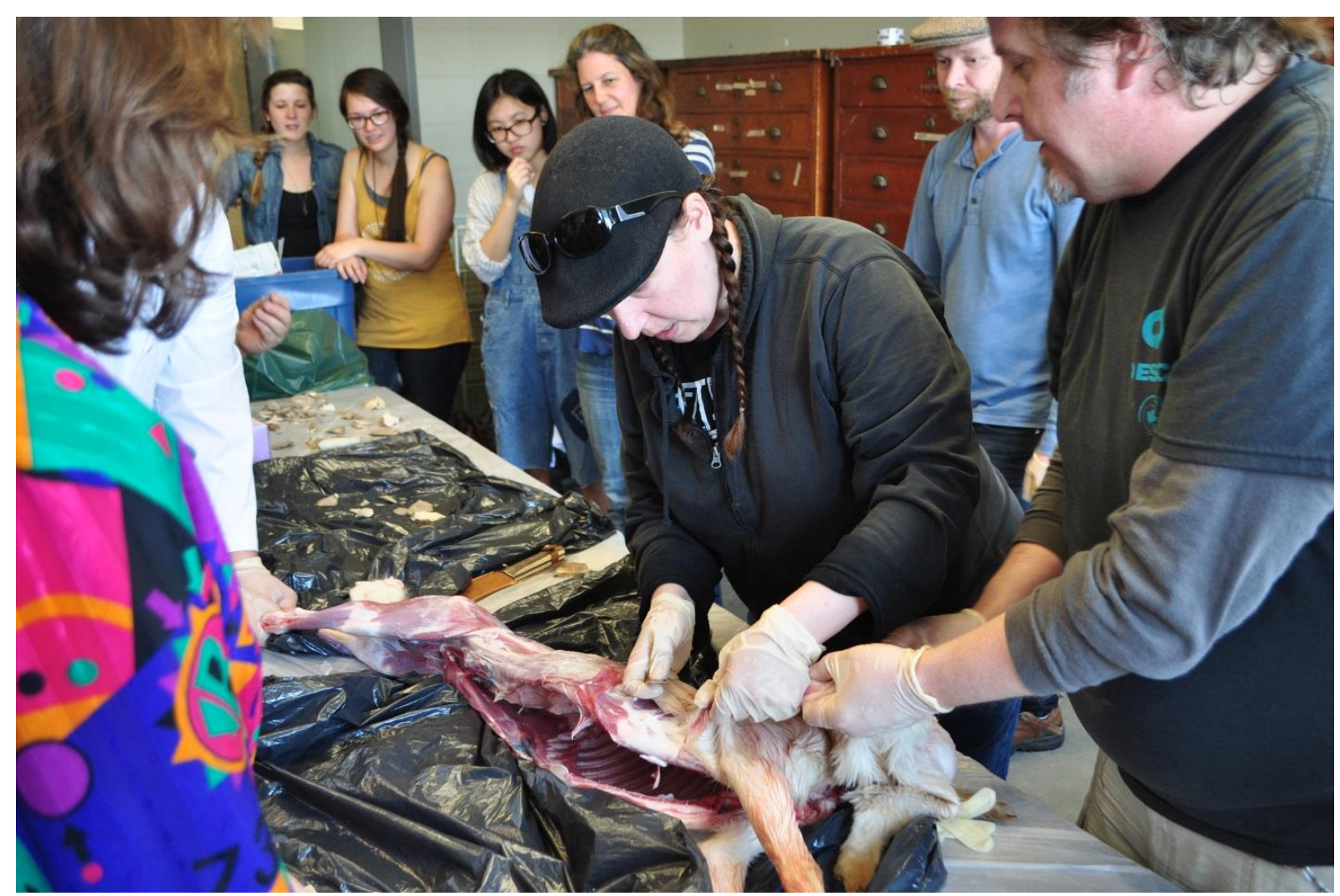

Figure 3. Skinning the goat with the knapped flakes. (Photo by Paulina Dobrota)

The knap-in and goat preparation event concluded when the participants were finished extracting all meat and hide from the goat. The following evening, after the resultant goat meat was marinated and otherwise prepped, the attendees celebrated their afternoon's work with a feast of goat sausage and kebabs at a potluck barbecue with a Mediterranean cuisine theme.

Starting from the practice of basic flake removal, to selecting and curating flakes for the required task, through to the animal butchering and finally the consumption of delicious barbecued goat, all participants were able to walk through the food extraction process and learn what it takes to both knap stone and put it to use. Attendees received a very visual and experiential lesson in the history of food production and the steps involved in extracting food and hide resources from animals.

More information about The Archaeology Centre and its Interest Groups can be found at www.archaeology.utoronto.ca . 


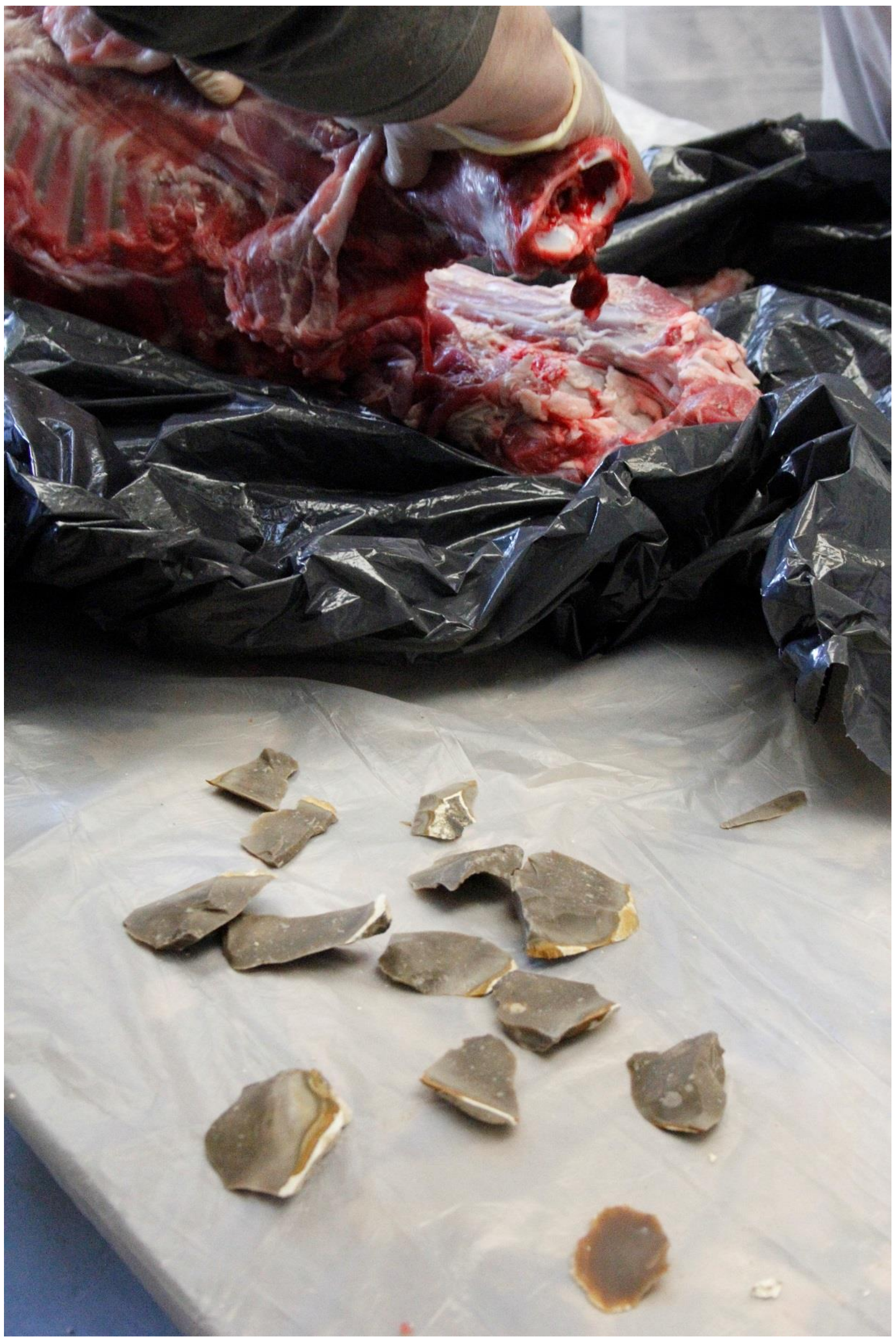

Figure 4. The students chose some of their flakes for work on the goat. (Photo by Amy Fox) 


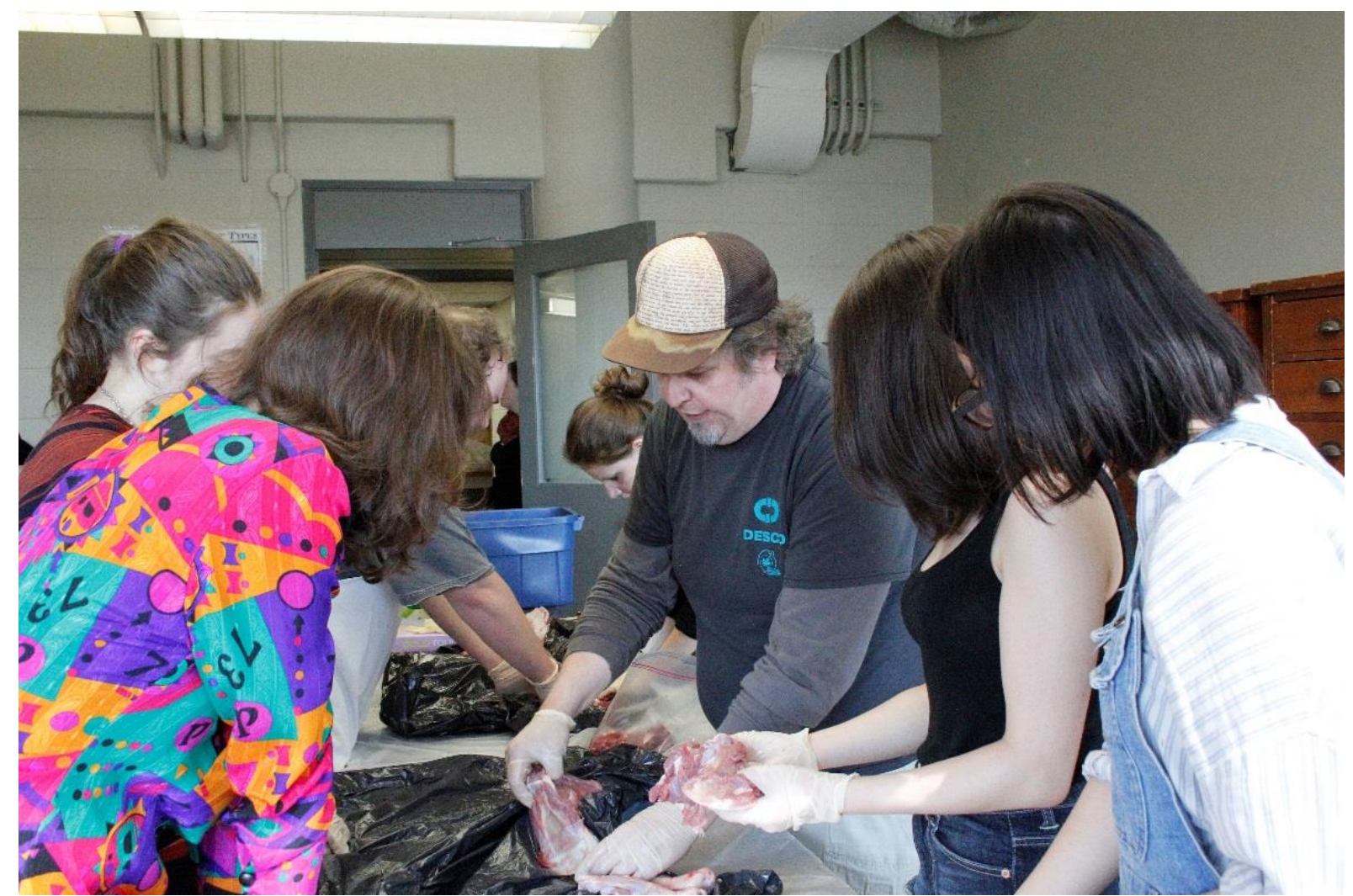

Figure 5. Students learn traditional butchering techniques. (Photo by Amy Fox)

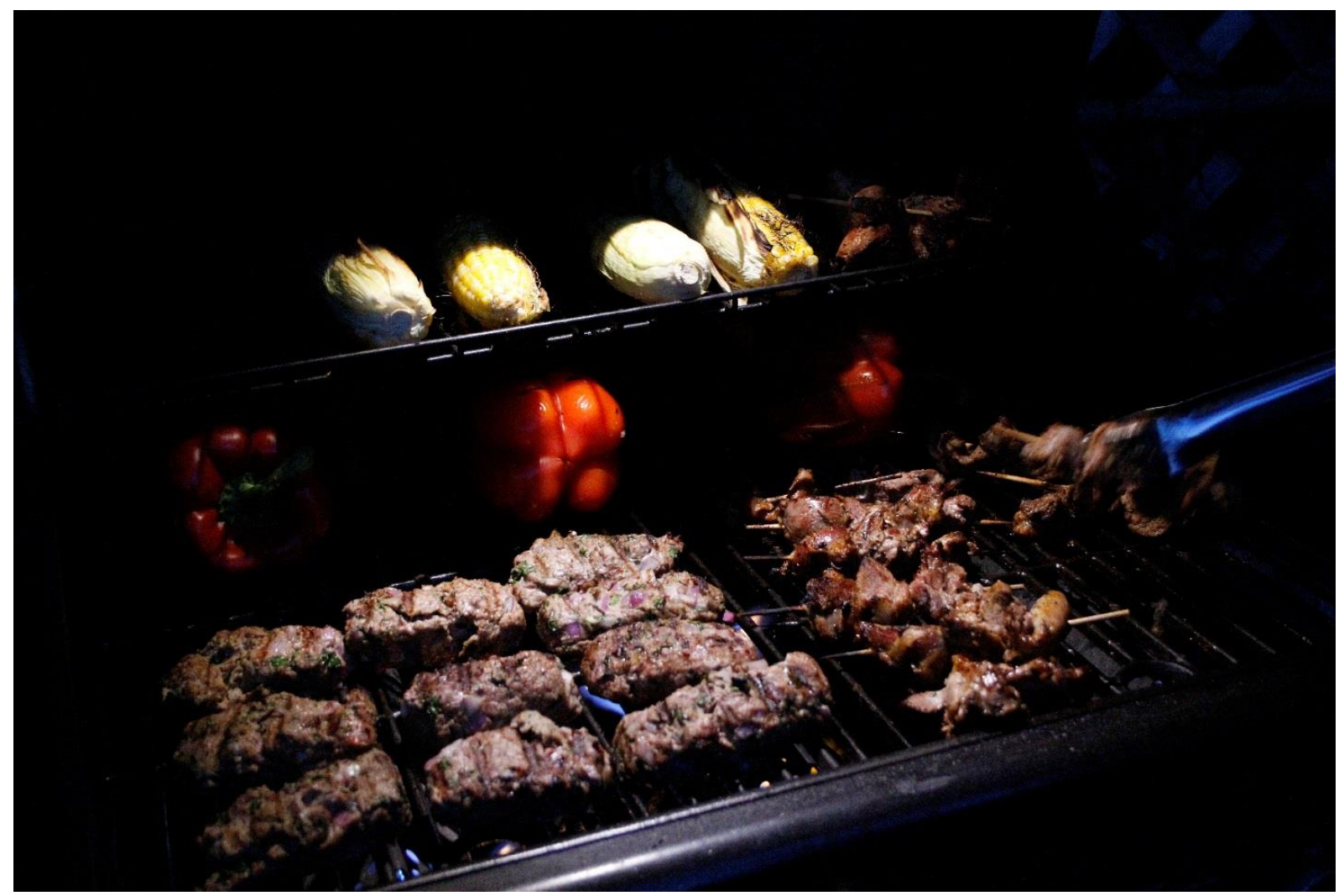

Figure 6. Goat sausage and kebabs. (Photo by Amy Fox) 